\title{
Optical properties of water and spectral light absorption by living and non-living particles and by yellow substances in coral reef waters of French Polynesia
}

\author{
Stéphane Maritorena*, Nathalie Guillocheau
}

Laboratoire d'Ecologie Marine, Université Française du Pacifique, BP 6570—Faaa/Aéroport, Tahiti, French Polynesia

\begin{abstract}
Spectral optical properties in different kinds of water were studied at several islands in French Polynesia. Optical differences between the waters of a high island (Moorea, Society archipelago), an atoll (Takapoto, Tuamotu archipelago) and the ocean above the outer reef slope were first assessed in terms of irradiance and diffuse attenuation coefficients. These differences were analysed with respect to the effect of phytoplankton, non-living particles and yellow substances, with these 2 latter components being responsible for most of the variations observed. Absorption coefficients for phytoplankton and non-living particles, as well as absorption by yellow substances, were also measured in the waters of the high island of Tahiti (Society archipelago) using the 'glass-fiber filter' technique and spectrophotometric measurements, respectively. These data showed large spatial variability of absorption, the main absorbing compound varying from one location to another depending on whether a station was mainly influenced by emergent land or by the ocean. Specific absorption coefficients for phytoplankton showed marked spatial and temporal variations among the stations. Spatial variations were related to concentrations of chlorophyll a and covarying pigments, taxonomic differences and total suspended particles. Temporal variations were probably caused by differences in the incident UV radiation between summer and winter These results show that optical properties of water can be used to describe the medium in aquatic environmental studies
\end{abstract}

KEY WORDS: Optical properties $\cdot$ Light absorption $\cdot$ Coral reefs

\section{INTRODUCTION}

Although light is an essential parameter in the functioning of coral reefs, some dimensions of this variable are, paradoxically, not well known in such environments. In fact, many light measurements have been conducted in coral reef waters, mostly in relation to photosynthetic processes by benthic or planktonic organisms, but most of these data are only concerned with the amount of available energy within the visible spectrum [photosynthetically available radiation $(\mathrm{PAR})=400$ to $700 \mathrm{~nm}$ ]. Other aspects of light (e.g. spectral behaviour, geometry) are poorly documented. As Falkowski

\footnotetext{
•E-mail: payri@tahiti.rio.net
}

et al. (1990) mentioned, '...there is relatively little information about the spectral nature of the underwater light field, especially on coral reefs'. To our knowledge, the only published spectral light measurements are those of Dustan (1982) and Maritorena et al. (1994).

The spectral dimension of light can be studied by examining several optical properties of water. Optical properties can be divided into 2 classes (Preisendorfer 1961): inherent properties and apparent properties. Inherent properties (e.g. absorption coefficient, scattering coefficient, volume scattering function) are independent of the ambient light field and depend only upon the nature and the composition of particles and dissolved substances in the medium. Unfortunately, inherent properties are difficult to measure. Similarly, apparent properties depend on the medium 
but also on the geometrical structure of the light field (i.e. the angular distribution of the underwater radiances). Apparent properties are more easily determined but they are sometimes difficult to interpret as they are influenced by numerous factors

Whatever the optical property considered, it is closely related to the water content in terms of living and non-living particles and optically active dissolved substances (i.e. yellow substances, hereafter referred to as YS). Hence, light is quantitatively and qualitatively altered within the water body due to absorption and scattering by the water constituents.

Knowledge of the optical properties of water in the lagoon and over the outer reef slope of coral reefs is important for numerous studies related to primary productivity, photophysiology or remote sensing

The aim of this paper is to present some spectral optical properties of the water column in coral reef waters of French Polynesia. These properties depend on the water content in terms of particulate and dissolved organic matter and can thus provide information on some of its characteristics. This paper is also an attempt to show that aside from classical applications in photosynthesis or remote sensing, optical properties of water may be used to describe the medium in aquatic environmental studies.

\section{MATERIAL AND METHODS}

Underwater irradiance measurements. Between June 1989 and June 1990, spectral irradiance measurements were carried out at 21 stations in French Polynesia (Fig. 1) Sixteen stations were located in the waters of the high island of Moorea (Society archipelago): 11 in the lagoon and 5 above the outer reef slope. Five stations were located in the lagoon of the atoll of Takapoto (Tuamotu archipelago). The measurements were recorded with a LICOR UW1800 underwater spectroradiometer every $5 \mathrm{~nm}$ between 400 and $700 \mathrm{~nm}$. At each station, downwelling irradiance was measured at several depths between 0 and $40 \mathrm{~m}$. An in-air spectrum was also recorded before and after the underwater measurements to check for variations in the incident irradiance. Downwelling irradiance measurements were obtained at all stations, whereas upwelling irradiances could only be measured at 11 stations. All lagoonal stations were located in deep zones to avoid bottom influence. All measurements were conducted under the following conditions: clear sky, calm sea, sun close to the zenith.

Water samples were collected on some occasions in order to assess chlorophyll a (chl a) content. Chl a and pheophytin a concentrations were determined fluorometrically (Turner 112 fluorometer) from acetone extracts according to Lorenzen (1966).
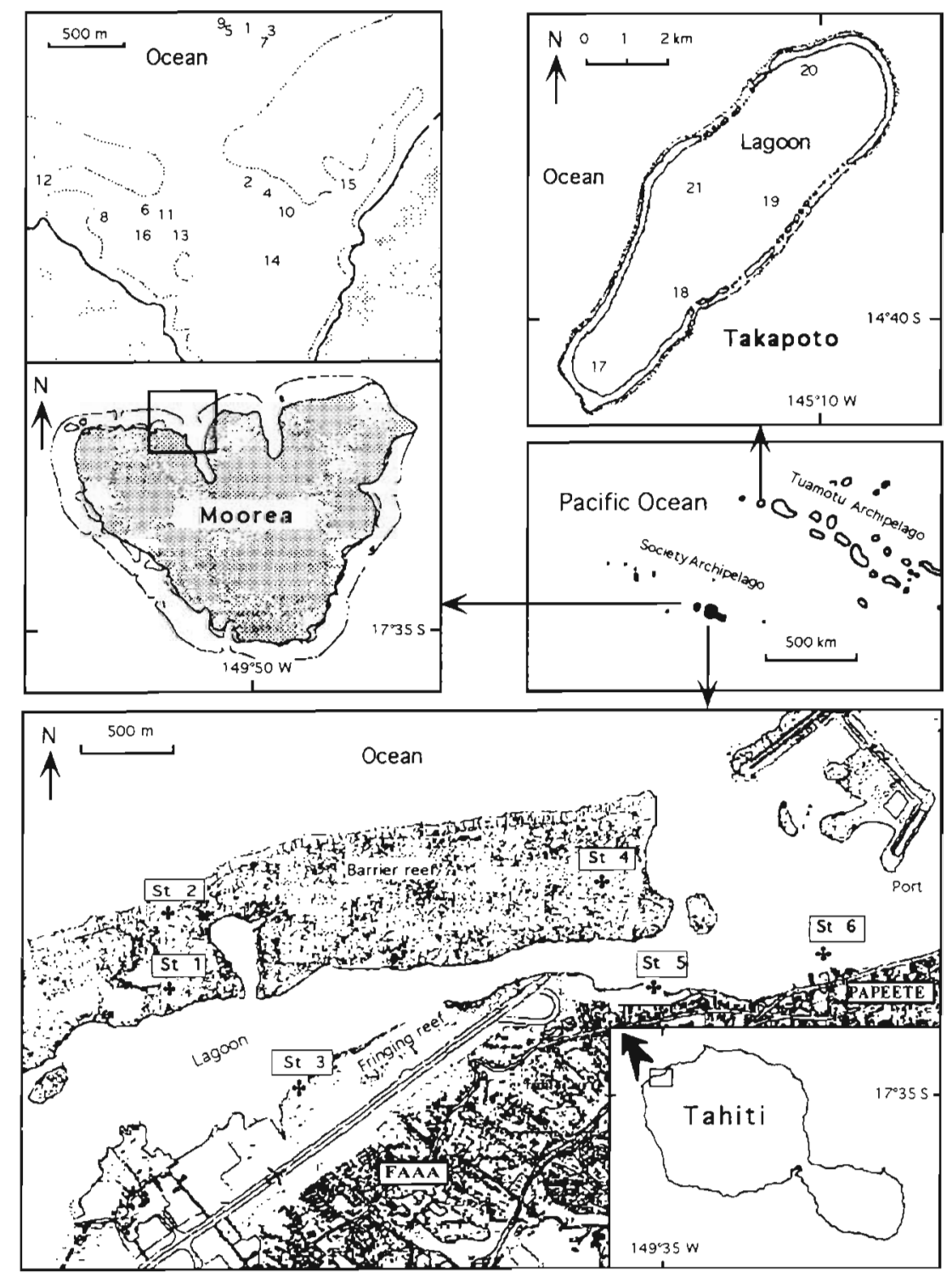

Fig. 1. Location of the stations for irradiance measurements (Moorea and Takapoto) and for absorption measurements (Tahiti) 
Absorption by particles and yellow substances. Sampling, total suspended particles, chlorophyll: Six stations were investigated in the lagoon of the high island of Tahiti (Society archipelago). Three stations were lacated in a 'protected' zone of the lagoon, that is, a zone with few influences of natural (= terrigenous) or anthropogenic (= urban) origin: Stn 1 was located on the barrier reef close to the lagoon; $\operatorname{Stn} 2$ was also on the barrier reef, but close to the outer ridge; and $\operatorname{Stn} 3$ was located on the fringing reef. The 3 other stations were located in a zone influenced by the port and the city of Papeete. Stn 4 was on the barrier reef close to the pass; Stn 5 was on the fringing reef; and Stn 6 was at the mouth of the Tipaerui River (Fig. 1).

Water samples were collected at all stations on 5 different dates in April 1993 and on 5 other occasions between December 1993 and January 1994. At each station, $10 \mathrm{l}$ was sampled and sieved through $50 \mu \mathrm{m}$ mesh gauze and kept in the dark at $4{ }^{\circ} \mathrm{C}$ until returned to the laboratory.

In the laboratory, $3 \mathrm{l}$ from the $10 \mathrm{l}$ sampled was filtered on preweighed Whatman GF/F filters which were rinsed with $10 \mathrm{ml}$ ammonium formate and dried for $24 \mathrm{~h}$ at $70^{\circ} \mathrm{C}$ for dry weight determinations of total suspended particles (TSP).

One litre was filtered on GF/F filters for chl $a$ and pheophytin a fluorometrical determinations (Lorenzen 1966). In order to assess the distribution of chl a in different size classes of phytoplankton, the same pigment measurements were also performed after a fractionated filtration of 11 on 3 successive Nuclepore filters of 10,2 and $0.2 \mu \mathrm{m}$ pore size, corresponding to micro-, nano- and picoplankton, respectively.

Light absorption by yellow substances: Low vacuum filtration of small volumes ( $300 \mathrm{ml}$ ) of water was carried out on Nuclepore $0.2 \mu \mathrm{m}$ filters. The filtrate was spectrophotometrically measured (Ciba Corning 2800 Spectrascan) at $375 \mathrm{~nm}$. The reference was distilled water. Optical densities (OD) at $375 \mathrm{~nm}$ were converted into absorption coefficients for YS, $a_{y}(375)\left(\mathrm{m}^{-1}\right)$ according to:

$$
a_{v}(375)=\frac{2.303 O D(375)}{l}
$$

where $l$ is the path length of the quartz cuvette (in m) and 2.303 a coefficient for transformation into natural logarithms (for symbols, definitions and units used in this paper see Table 1). A complete spectrum between 375 and $725 \mathrm{~nm}$ is obtained according to the exponential decay model of Bricaud et al. (1981):

$$
a_{y}(\lambda)=a_{Y^{\prime}}(375) \exp [-0.014(\lambda-375)]
$$

Light absorption by living and non-living particles: For each water sample, a GF/F filter was rehydrated for $1 \mathrm{~h}$ in distilled water and marked to ensure that the orientation of the filter was identical for all measurements. A blank spectrum was first recorded in transmission mode with a 1800-12 LI-COR integrating sphere connected to the spectroradiometer. After this scan, 2 to 61 of water was filtered on the filter used for the blank and another scan was immediately performed after filtration. After this second scan, the filter was immersed in absolute methanol at $4^{\circ} \mathrm{C}$ for $1.5 \mathrm{~h}$ for pigment extraction (Kishino et al. 1985). The filter was rehydrated and a third scan recorded. These 2 latter spectra were then divided by the blank spectrum to obtain the transmission value $T_{i}(\lambda)$.

The absorption coefficient for total particles (chlorophyllous and non-chlorophyllous), $a_{p}(\lambda)$, and for nonchlorophyllous particles, $a_{d}(\lambda)$, can then be calculated according to:

$$
a_{1}(\lambda)=\frac{-2.303 \log T_{i}(\lambda)}{\beta\left(\frac{V}{S}\right)}
$$

(unit: $\mathrm{m}^{-1}$ ), where the subscript $i$ stands for total particles, $p$, or non-chlorophyllous particles, $d ; \beta$ is the amplification factor (Butler 1962); $V$ is the filtered volume; $S$ is the clearance area of the filter; and 2.303 is for transforma-

\begin{tabular}{|c|c|c|}
\hline Symbol & Definition & Unit \\
\hline$\lambda$ & Wavelength & $\mathrm{nm}$ \\
\hline$a_{\mathrm{d}}(\lambda)$ & Absorption coefficient of non-chlorophyllous particles & $m^{-1}$ \\
\hline$a_{p}(\lambda)$ & Absorption coefficient of total particles & $m^{-1}$ \\
\hline$a_{\mathrm{ph}}(\lambda)$ & Absorption coefficient of phytoplankton & $m^{-1}$ \\
\hline$a^{*}{ }_{\mathrm{ph}}(\lambda)$ & Chl a-specific absorption coefficient of phytoplankton & $\mathrm{m}^{2} \mathrm{mg}^{-1}$ \\
\hline$a_{y}(\lambda)$ & Absorption coefficient of yellow substances & $m^{-1}$ \\
\hline$\beta$ & Path length amplification & - \\
\hline [chl $a+$ pheo] & Chl $a+$ pheophytin a concentration & $\mathrm{mg} \mathrm{m}^{-3}$ \\
\hline$E_{\mathrm{d}}(\lambda, z)$ & Downwelling irradiance at depth $z$ & $W \mathrm{~m}^{-2} \mathrm{~nm}^{-1}$ \\
\hline$K_{\mathrm{d}}(\lambda, z)$ & Diffuse attenuation coefficient for downwelling irradiance & $m^{-1}$ \\
\hline TSP & Dry weights of total suspended particles & $\mathrm{mg} \mathrm{l^{-1 }}$ \\
\hline$z$ & Depth & $\mathrm{m}$ \\
\hline
\end{tabular}
tion into natural logarithms. As absorbances derived

Table 1. Symbols and units used in this paper 
from transmission measurements were always greater than 0.2 in the 375 to $600 \mathrm{~nm}$ range, $\beta$ is assumed to have weak spectral variations (Mitchell \& Kiefer 1988a, Bricaud \& Stramski 1990, Nelson \& Robertson 1993). However, $\beta$ was calculated at each wavelength according to the expression of Bricaud \& Stramski (1990) for GF/F filters. Absorption by chlorophyllous particles, $a_{\mathrm{ph}}(\lambda)$, is then given by:

$$
a_{\mathrm{ph}}(\lambda)=a_{\mathrm{p}}(\lambda)-a_{\mathrm{d}}(\lambda)
$$

The specific absorption coefficient by phytoplankton $\left[a^{*}{ }_{\mathrm{ph}}(\lambda), \mathrm{m}^{2}\right.$ (mg chl a + pheo $\left.)^{-1}\right]$ is calculated as follows:

$$
a_{p h}^{*}(\lambda)=\frac{a_{p h}(\lambda)-a_{p h}(750)}{[\text { chl } a+\text { pheo] }}
$$

where [chl a + pheo] is the sum of the concentrations of chl $a$ and pheophytin $a$, and $a_{p h}(750)$ is the absorption coefficient at $750 \mathrm{~nm}$. This value is subtracted at all wavelengths, as absorption by pigments can be considered as being null at this wavelength (Bricaud \& Stramski 1990).

\section{RESULTS AND DISCUSSION}

\section{Irradiance}

The main features of downwelling irradiance in the deep lagoonal zone are: (1) a strong decrease of irradiance with depth beyond $575 \mathrm{~nm}$; (2) a lower decrease at short wavelengths; and (3) the appearance of a peak at around $675 \mathrm{~nm}$ for deep spectra (Fig. 2). The first 2 patterns are mainly due to the absorption properties of the water column which are discussed below (see 'Diffuse attenuation coefficient' and 'Conclusions') The third pattern is probably caused by sun induced fluorescence of phytoplankton chl a (see e.g. Gordon 1979, Kishino et al. 1984, Topliss 1985). Because underwater irradiance depends on the incident light field at the surface, it is difficult to compare irradiance spectra from different stations or at different dates. For such comparisons, it is more meaningful to work with spectra at the same optical depth instead of at the same geometrical depth. For our data, and in order to compare the different stations, the optical depth was arbitrarily fixed at the level where $15 \%$ of the surface PAR remained. When normalised by their maximum, data from the outer reef slope showed high values at short wavelengths and rapidly decreasing values beyond the maxima (Fig. 3). An inverse trend was observed for lagoonal stations, i.e. relatively high values beyond the maximum, at least in the 490 to $575 \mathrm{~nm}$ range, compared to those at shorter wavelengths. In both cases, irradiance was very low beyond $600 \mathrm{~nm}$. Schematically, these patterns can be attributed mainly to particulate and/or YS absorption before the maximum and to water absorption after it. Spectral irradiance profiles can be used to describe the light field at a particular station on a particular day or to show the extreme light conditions living organisms may experience. The shape of irradiance spectra may also provide information on the contents of the water However, because of its dependence on the incident light field, irradiance is not the best parameter for spatial or temporal comparisons 


\section{Diffuse attenuation coefficient}

When spectral downwelling irradiance measurements are available at several depths at a station, the diffuse attenuation coefficient for downwelling irradiance can be derived by:

$$
K_{\mathrm{d}}(\lambda)\left(z_{1}, z_{2}\right)=\frac{1}{z_{1}-z_{2}} \ln \frac{E_{\mathrm{d}}\left(\lambda, z_{1}\right)}{E_{\mathrm{d}}\left(\lambda, z_{2}\right)}
$$

where $E_{\mathrm{d}}\left(\lambda, z_{1}\right)$ and $E_{\mathrm{d}}\left(\lambda, z_{2}\right)$ are the irradiance at wavelength $\lambda$ and at depths $z_{1}$ and $z_{2}$, respectively (with $z_{2}>$ $z_{1}$ ). The same equation can be used for upwelling irradiances. The spectral diffuse attenuation coefficient for downwelling irradiance describes qualitatively and quantitatively the decrease of light energy with depth. Attenuation results both from absorption and scattering. Although it is an apparent property, it has been shown that when irradiance is obtained under sea, sun and sky conditions similar to those under which we experimented, attenuation can be considered as a 'quasi-inherent' property (Baker \& Smith 1980, Kirk 1984, Gordon 1989a, b)

Attenuation spectra show 2 main patterns: (1) low values in the 400 to $570 \mathrm{~nm}$ range; and (2) increasing values beyond $570 \mathrm{~nm}$, essentially caused by the strong absorption of the water itself at long wavelengths. In Fig. 4, spectra from the outer reef slope, from the lagoon of the atoll of Takapoto and from the lagoon of Moorea are sorted by their attenuation at $400 \mathrm{~nm}$. At this wavelength, $K_{\mathrm{d}}$ varied between $0.03 \mathrm{~m}^{-1}$ (Stn 5 outer reef slope) and $0.184 \mathrm{~m}^{-1}$ (Stn 14, Opunohu Bay Moorea). Except at 2 stations, the 3 kinds of water sampled were clearly separated. The outer reef slope waters were the clearest, with $K_{\mathrm{d}}$ varying between type I and type II of the optical classification of Jerlov (1976) (for discussion about the discrepancies between in situ data and Jerlov's values of $K_{\mathrm{d}}$ see e.g. Pelevin \& Rutkovskaya 1977, Morel 1988). For these stations, the spectra were almost flat between 400 and $500 \mathrm{~nm}$, the minimum value drifting around $480 \mathrm{~nm}$. The influence of emerged zones was of course stronger in the case of Moorea and resulted in increased absorption and scattering (and thus attenuation) by particles and YS.

In Case 1 waters (i.e. waters for which optical properties are dominated by phytoplankton; Morel \& Prieur 1977) and due to its 'quasi-inherent' property, total attenuation, $K_{\mathrm{d}}(\lambda)$, can be divided into several components according to:

$$
K_{\mathrm{d}}(\lambda)=K_{\mathrm{w}}(\lambda)+K_{\mathrm{c}}(\lambda)+K_{\mathrm{x}}(\lambda)
$$

where $K_{w}(\lambda)$ is the attenuation caused by the water itself, $K_{c}(\lambda)$ is the part of attenuation caused by phytoplankton and $K_{x}(\lambda)$ is the attenuation by other particles and dissolved organic matter (DOM) (see Baker \& Smith 1980, Kirk 1984, Stavn 1988, Gordon 1989a for discussion). $K_{\mathrm{w}}(\lambda)$ can be derived from the absorption and scattering data for 'pure seawater' (Morel \& Prieur 1977. Smith \& Baker 1981), and $K_{c}(\lambda)$ can be computed with recent bio-optical models which relate attenuation to pigment concentration (Smith \& Baker 1978a, b, Baker \& Smith 1982, Morel 1988).

For 3 of the clearest stations that had available pigment data and were assumed to have Case 1 waters (Stns 3, 5 and 6; see Fig. 4), total attenuation derived from in situ measurements was compared to total attenuation estimated from Eq. (7). This latter estimation was obtained by using Morel's model (1988) for $K_{c}(\lambda)$ and data from Smith \& Baker (1981) for $K_{\mathrm{w}}(\lambda)$. The agreement between measured and computed values appeared to be good in the 400 to $600 \mathrm{~nm}$ range (Fig. 5). At longer wavelengths, the differences are due to greater inaccuracies both for models and in situ data. The good concordance at short wavelengths confirms that these stations have Case 1 waters. This point is questionable for less clear stations in lagoonal waters. The same approach as described above can, however, be used in order to quantify the magnitude of the $K_{\mathrm{x}}$ term, which is given by subtracting $K_{\mathrm{w}}$ and $K_{\mathrm{c}}$ from $K_{\mathrm{d}}$. This was done for 13 stations, including Stns 3, 5

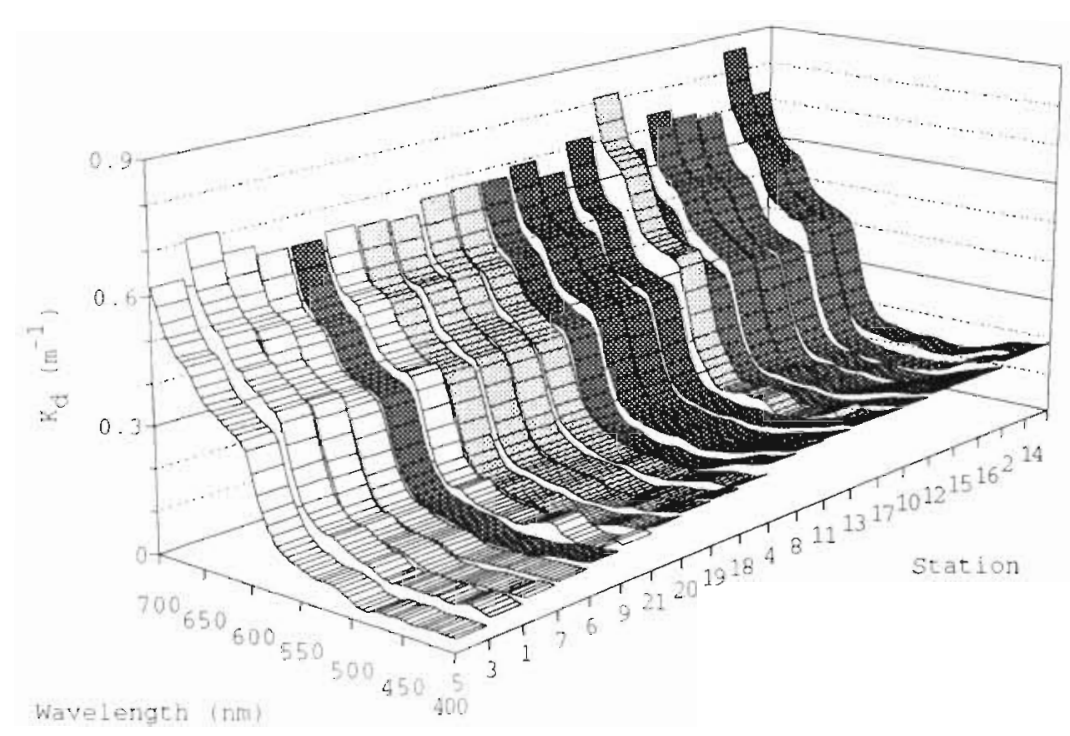

Fig. 4. Diffuse attenuation coefficient spectra of the 21 stations where irradiance measurements were conducted. Spectra from the outer reef slope (white pattern), from the lagoon of Moorea (dark grey pattern) and from the lagoon of Takapoto (light grey pattern) are sorted by their values at $400 \mathrm{~nm}$ 

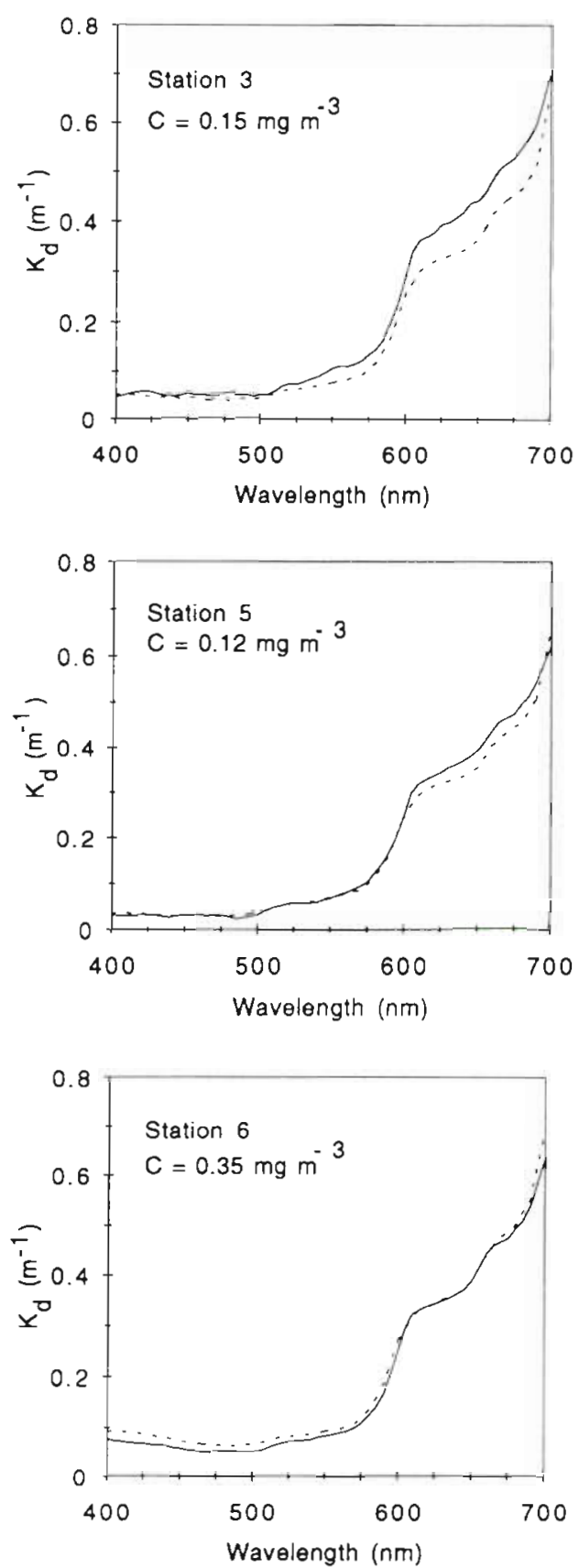

Fig. 5. Comparison between total attenuation derived from irradiance measurements at Stns 3,5 and 6 (solid curves) and attenuation computed using Morel's model (1988) (dashed curves) C: chlorophyll a + pheophytin a concentrations

and 6 (Fig. 6). In waters from the outer reef slope and from Stn 6 (Moorea), the $K_{\mathrm{x}}$ term is close to zero as in Case 1 waters. For all other stations, the $K_{\mathrm{x}}$ term cannot be considered as being null, with $K_{\mathrm{x}}(400)$ varying from 0.04 to $0.104 \mathrm{~m}^{-1}$ The general trend of these spectra shows a decrease in $K_{\mathrm{x}}$ between 400 and $575 \mathrm{~nm}$ and higher $K_{\mathrm{x}}$ values beyond $600 \mathrm{~nm}$. In most cases, $K_{\mathrm{x}}$ was greater in Moorea than in Takapoto because of the greater influence of emerged zones. It must, however, be kept in mind that $K_{\mathrm{x}}$ reflects both absorption and scattering by YS and non-chlorophyllous particles and that it remains weak compared to absorption by DOM or particles found in the literature

From attenuation data, it is, however, difficult to draw conclusions about the optical classification of lagoonal waters. They may sometimes be considered as Case 1 waters (e.g. Stn 6) or may have a detrital component which cannot be neglected. It is reasonable to assume that lagoonal waters alternate between Case 1 and Case 2, depending on (1) the amount of rainfall, (2) the part of the lagoon considered, (3) the magnitude of water exchange between the lagoon and the ocean, and (4) the general organisation of the lagoon.

Another way to compare stations or islands is to calculate the spectral reflectance from up- and downwelling irradiance at null depth [i.e. $R\left(\lambda, 0^{-}\right)=$ $\left.E_{u}\left(\lambda, 0^{-}\right) / E_{d}\left(\lambda, 0^{-}\right)\right]$. Typical spectra of clear oligotrophic Case 1 waters were encountered in the outer reef slope. High molecular scattering by the water and low absorption by particulate matter and DOM led to a maximum of reflectance around $400 \mathrm{~nm}$. In lagoonal waters, enhanced amounts of blue absorbing materials resulted in dropped reflectances at short wavelengths and a shift of the maximum around $480 \mathrm{~nm}$. In the red part of the spectrum, enhanced scattering by particulate material entailed increased reflectance (for a more detailed analysis of reflectance spectra in coral reef waters, see Maritorena et al. 1994, Maritorena 1996).

As irradiance profiles (and derived quantities such as attenuation or reflectance) are restricted to deep zones ( 15 to $40 \mathrm{~m}$ ), the spatial variability of optical properties could not be assessed completely from these data. However, this limitation could be circumvented by working with absorption, as this parameter is obtained from water samples that can be collected anywhere on the reef

\section{Absorption coefficient of phytoplankton, non- chlorophyllous particles and yellow substances}

Depending on the geomorphological location of the stations, absorption appeared to be dominated by different components. The general trends for each component and at each station can be illustrated by mean absorption coefficient spectra (Fig. 7). For both stations on the barrier reef in the 'protected zone' (Stns 1 and 2), absorption by phytoplankton and by non-chlorophyllous particles prevailed most of the time. At $440 \mathrm{~nm}$, the wavelength of the absorption maximum by chl $a_{1} a_{d}(440)$ was slightly greater than 
Fig. 6. Spectra of the residual attenuation, $K_{\mathrm{x}}$ for 13 stations from the outer reef slope (bold dashed curves), Moorea (solid curves) and Takapoto (dotted curves)
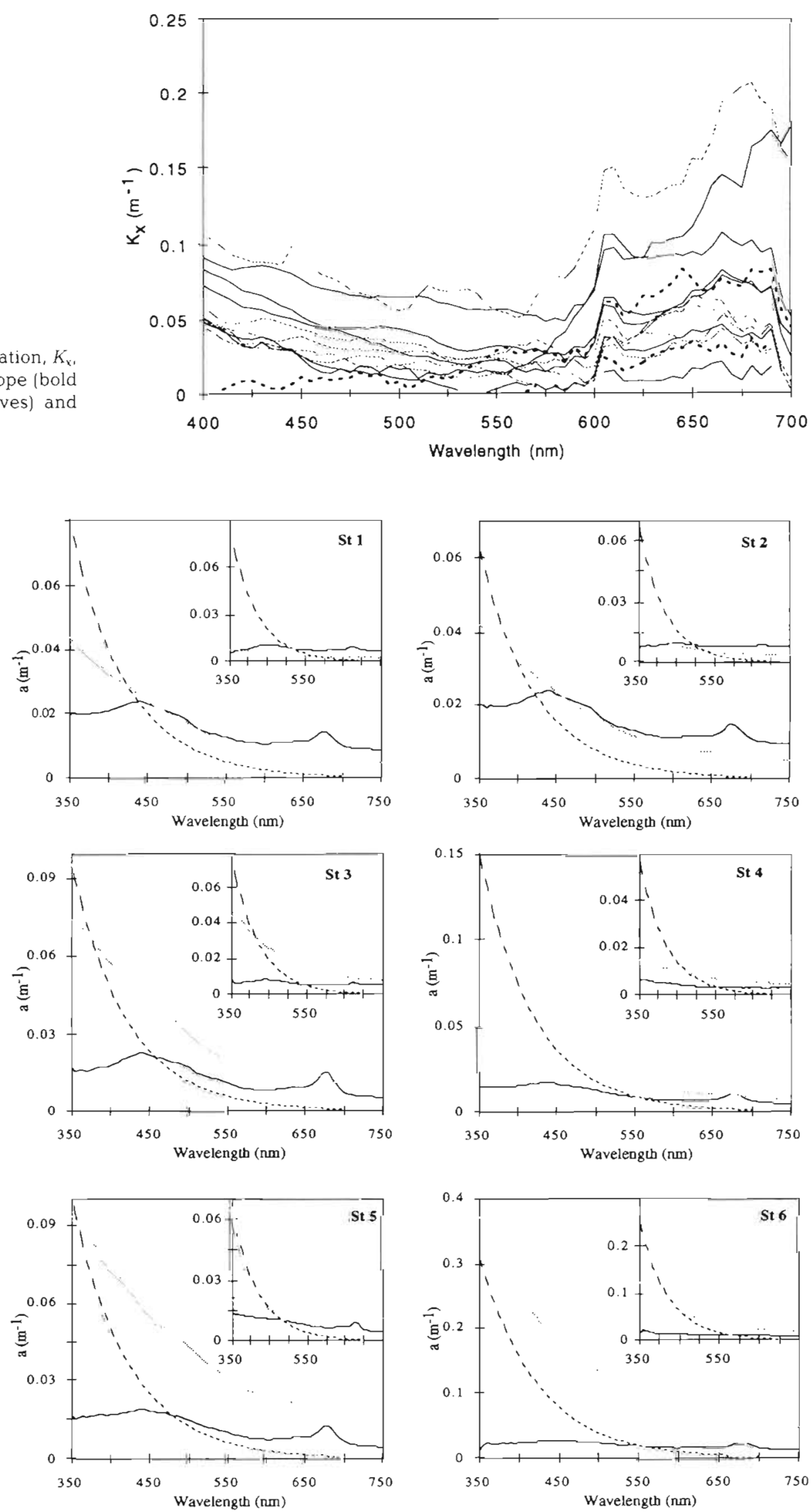

Fig. 7. Mean absorption coefficient spectra of yellow substances (dashed curves), phytoplankton (solid curves) and non-chlorophyllous particles (dotted curves) at the 6 stations where absorption measurements were conducted. Standard deviations are indicated in the insets 
$a_{p h}(440)$. However, at these stations absorption by phytoplankton and absorption by non-chlorophyllous particles were almost equal and phytoplankton sometimes played a predominant part. For these stations, absorption by YS was generally lower than absorption by living or non-living particles, but it was predominant on 1 occasion. Absorption by YS was highly variable at all stations (see standard deviations in Fig. 7). It must be mentioned that when no rainfall occurred for a few days, levels of YS were generally low, and in these situations, OD values measured with the spectrophotometer were sometimes close to the limit of sensitivity.

Stn 3 was more variable, as light absorption could be dominated either by the particulate or the soluble fraction. In most cases, non-chlorophyllous particles were the major absorbing component. Although absorption by phytoplankton was generally lower than by other particles, the difference between these 2 components remained weak. It must be noted that at Stn 3, mean [chl a + pheo] values were the highest, after those of Stn 6, and mean TSP values were the lowest (Fig. 8).

At the station on the barrier reef close to the port (Stn 4), light absorption was mainly dominated by YS and, to a lesser extent, by non-chlorophyllous particles (see Fig 7). Compared to the other components, absorption by phytoplankton was weak. Stn 4 showed highly variable TSP and high proportions of pheophytin a (see Fig. 8).

At Stn 5, absorption was strongly dominated by nonchlorophyllous particles, whereas the contribution of phytoplankton and YS was highly variable

The strongest absorptions were encountered at Stn 6 in front of the Tipaerui River $\left(0.67\right.$ and $0.56 \mathrm{~m}^{-1}$ at $375 \mathrm{~nm}$ on 31 December 1993 for YS and non-chlorophyllous particles, respectively). Absorption was mainly caused by non-chlorophyllous particles, as it was at this station that the highest TSP were measured. Stn 6 also had the highest concentrations of chl a+ pheo but absorption by pigments remained weak compared to other components

Despite the choice of sampling periods (in dry and rainy seasons) no significant differences appeared between the 2 sets of data. Because heavy rains did not occur during sampling, no data was available with high loads of terrigenous particles and YS, which may sometimes lead to brown coloured waters in the lagoon. In these situations, absorption is likely to rise to levels much higher than what we observed during our experiments. However, this only occurs during tropical depressions or cyclones, which are rare in French Polynesia. Furthermore, these events only last a few days, as the medium is quickly regenerated due to water exchanges with the ocean.
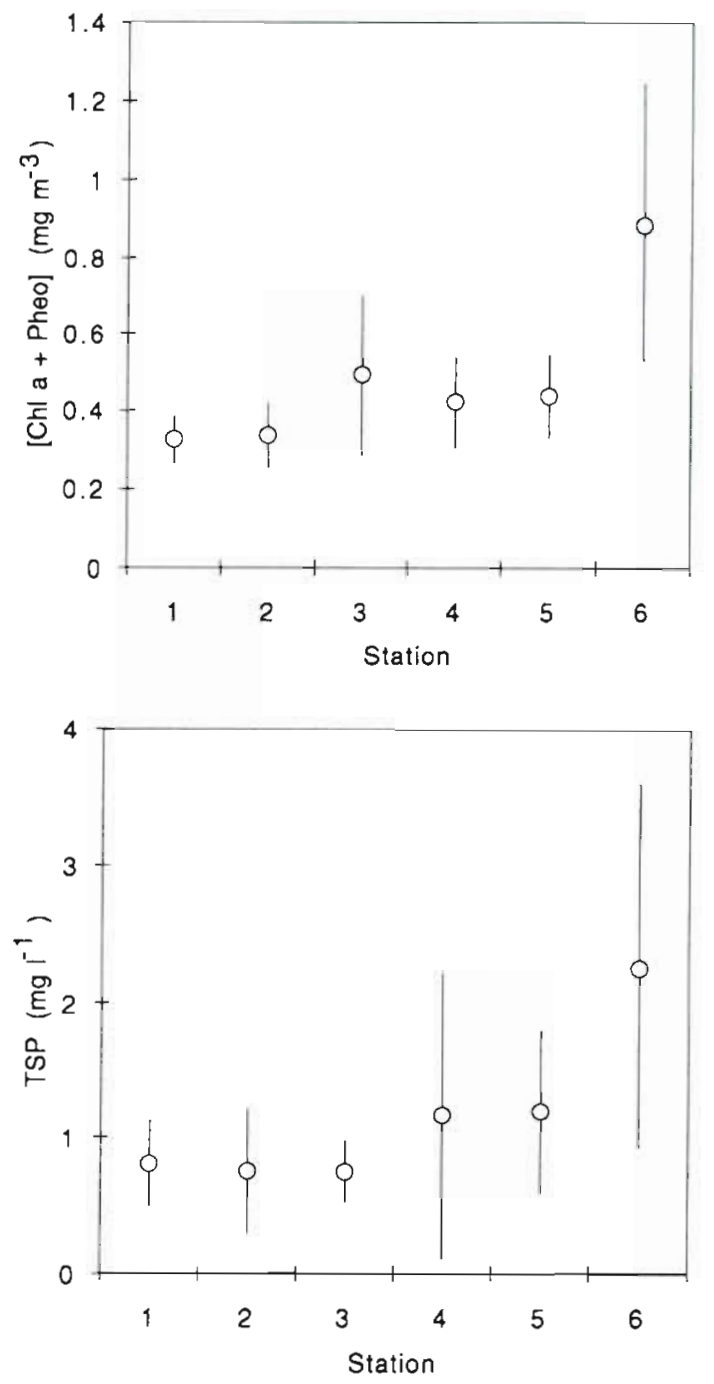

Fig. 8. Upper panel: mean [chl a + pheo] and standard deviation at each station. Lower panel: mean TSP and standard deviation

\section{Specific absorption}

The specific absorption coefficient spectra show 2 peaks mainly caused by chl a, one at around $440 \mathrm{~nm}$ and a smaller one centered at around $675 \mathrm{~nm}$. On several occasions, absorption by chl $b$ could be observed at around 480 and $650 \mathrm{~nm}$. When considering the coefficient of variation at $440 \mathrm{~nm}$ for each station (i.e. the ratio of the standard deviation to the mean), the variability appears to be important at Stns 5 and 6 . Conversely, Stns 1, 2, 4, and to a lesser extent Stn 3 appear less variable (Fig 9). It is clear from Fig. 9 that high specific absorption values correspond to the clearest waters (Stns 1, 2 and 3) and that specific absorption decreases with increasing turbidity (Stns 4, 5 and 6). The behaviour of $a_{\text {ph }}^{*}(\lambda)$ may also be attributed to [chl a + 


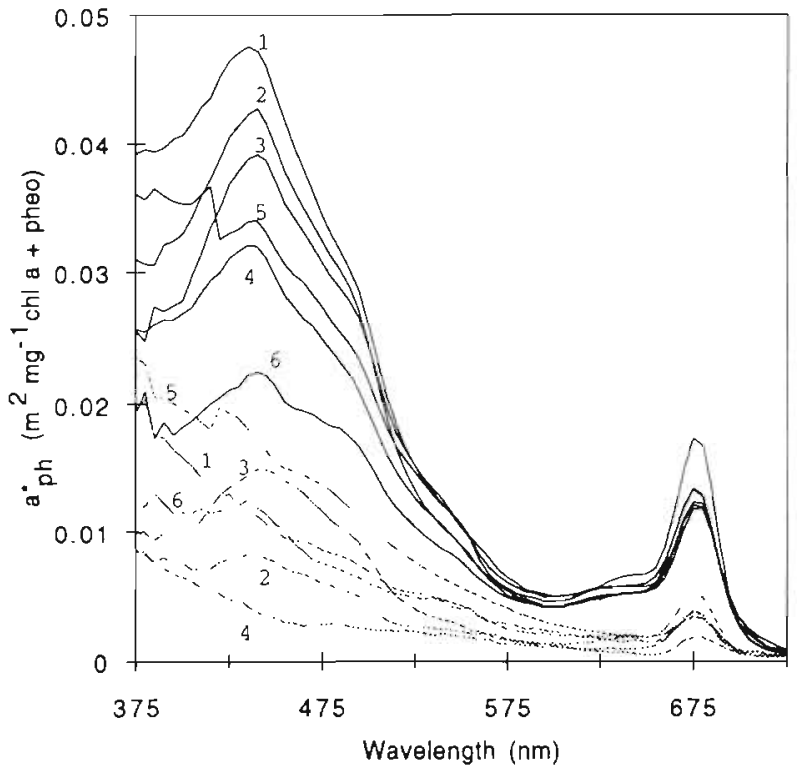

Fig. 9. Mean specific absorption coefficient of phytoplankton at each station (solid curves) and standard deviation (dotted curves). Stations are indicated by number

pheo], as it has been shown that these 2 parameters are inversely related (Fig. 10) (see e.g Mitchell \& Kiefer 1988b, Bricaud \& Stramski 1990, Babin et al. 1993).

At short wavelengths (350 to $440 \mathrm{~nm}$ ), large differences were sometimes observed between measurements at the same station. These differences mainly occurred between data collected in April and those obtained in December-January (Fig. 11). This temporal variability in the UV and blue parts of the spectrum appeared at all stations, except perhaps at Stn 3 . This

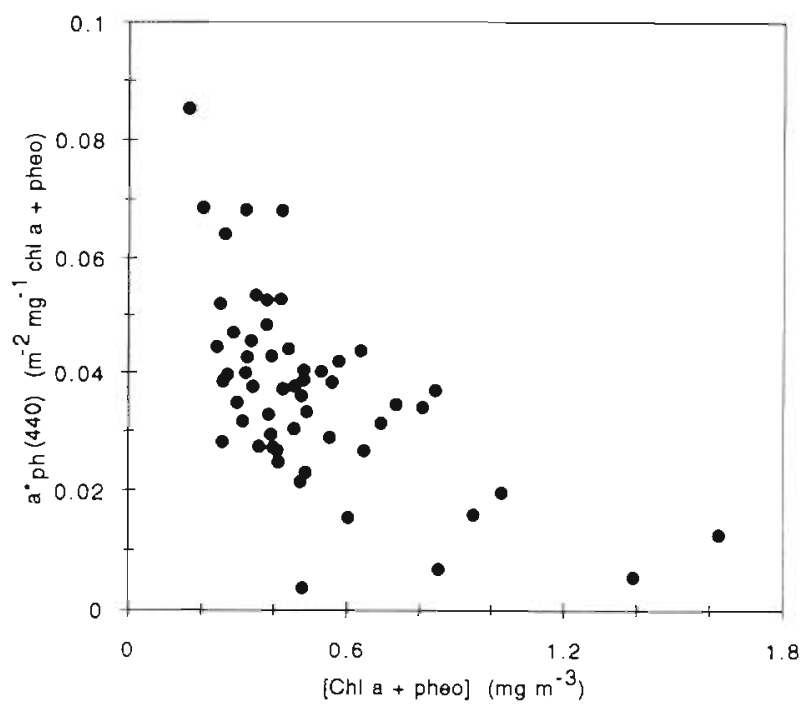

Fig. 10. Specific absorption at $440 \mathrm{~nm}$ as a function of [chl a + pheol for all samples

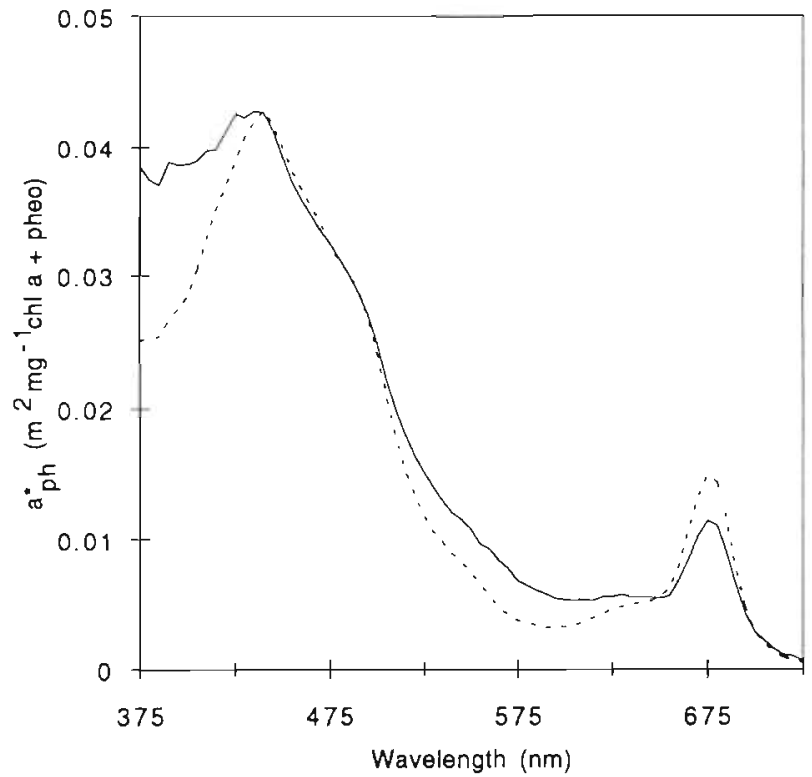

Fig. 11. Mean spectra of the Apnl sampling perlod (dashed curve) and of the December-January sampling period (solid curve) at Stn 2

stronger absorption at short wavelengths during summer could have resulted from development of photoprotectant compounds (carotenoids or mycosporinelike amino acids) as incident UV and PAR were respectively 20 and $30 \%$ higher in December than in April (Drollet et al. 1994). Yentsch \& Phinney (1989) observed the same kind of variations in the western North Atlantic Ocean.

Variations in the specific absorption depend on numerous parameters such as species, size of cells, pigment content or the physiological state of cells (see Bricaud et al. 1995 and references therein for a review on $a_{p h}^{*}(\lambda)$ variations). As previously mentioned for carotenoids, variations in accessory pigments content may have contributed to some of the variability observed. As specific absorption is normalised by the sum of chl $a+$ pheo $a$, the relative proportion of each pigment may vary and explain part of the observed variations. Variations in the cell size and/or intracellular pigment content result in the package effect (Kirk 1975), which is often considered as the main cause of variations in $a^{*}{ }_{p h}(\lambda)$. In our case, part of the variations may have come from differences in the relative proportion of chl $a$ in the different size classes of phytoplankton, as the proportion of total chl a in different microplankton fractions at each station increased in the same way as specific absorption (Fig. 12). The red absorption maximum is generally less influenced by accessory pigments and the package effect, so that variations in $a^{*}$ ph $(675)$, and consequently at other wavelengths, may have come from uncertainties in measurements of chl a 


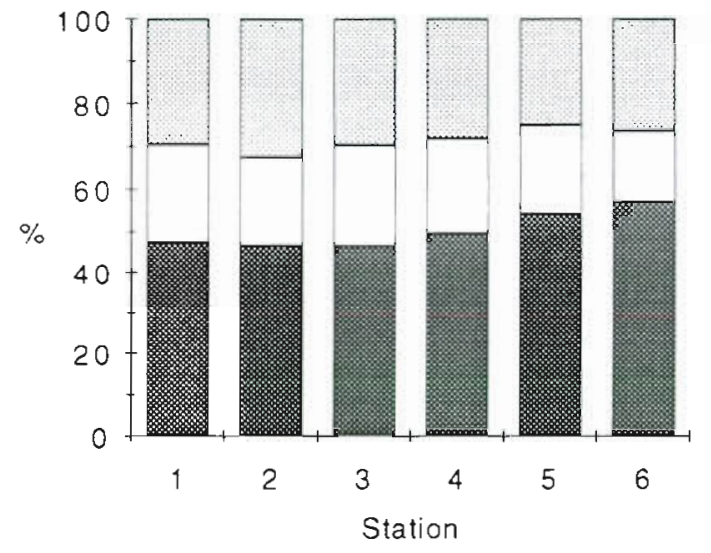

Fig. 12. Mean percentage of the total chlorophyll in the microplanktonic fraction (dark grey), nanoplanktonic fraction (white) and picoplanktonic fraction (light grey) at each station

concentrations. However, a complete analysis of variations in $a^{*}{ }_{\text {ph }}(\lambda)$ would entail measurement of all photosynthetic pigments, accurate counting and size determination of phytoplanktonic cells.

\section{CONCLUSIONS}

In this paper, aspects of the optical properties of waters associated with tropical coral reef ecosystems were reported. We have presented our results with particular attention to particulate content and dissolved material in the water. Spectral optical data may, however, be useful in investigating other biological or ecological topics.

Spectral irradiance is a good descriptive parameter of the aquatic environmental medium. It allows the available energy at a particular depth and at a particular location to be known at each wavelength. The shape of irradiance spectra is mostly influenced at the two ends of the spectrum. This results from absorption and scattering phenomena caused by the water itself and the particulate and dissolved material it contains. Spectral irradiance is also important in photosynthesis studies. Total irradiance in the visible range (PAR) is now frequently measured by many marine scientists, mostly in relation to primary production. Because photosynthesis is a quantum process, the total number of quanta, as given by PAR, is generally considered a useful parameter in primary production studies. Actually, because quantum efficiency of photosynthesis depends on the spectral characteristics of the light field, it cannot be accurately estimated from PAR measurements. Spectral irradiance is therefore a preferable parameter. Analysis of the water content as well as spatial and temporal comparisons between stations are, however, difficult to conduct using irradiance, as it is an apparent property. This can be circumvented by deriving relevant quantities from irradiance such as attenuation or reflectance.

Diffuse attenuation is also an apparent property, but it may be considered as 'quasi-inherent' under certain conditions. As it governs light penetration with depth, attenuation is relevant to numerous fields in marine science. Attenuation can be separated into several components. The relative contributions of these components to total attenuation can therefore provide information on the quality of the water. Attenuation is also an important parameter for remote sensing studies in shallow water zones. For instance, bottom recognition is improved when the influence of the water column above the bottom can be removed from the total radiance measured by the satellite. This can be achieved when attenuation is known in the wavebands used (see e.g. Lyzenga 1981, Maritorena et al. 1994, Maritorena 1996). A knowledge of attenuation may also help in bathymetry determination.

Spectral reflectance is a major parameter in ocean color research. Such data were not shown here because they were presented in previous papers (Maritorena et al. 1994, Maritorena 1995). Reflectance clearly separates the blue oligotrophic Case 1 waters of the outer reef slope from the rather green (Case 1 or Case 2) waters of the lagoons. Attenuation and reflectance are good parameters for comparison of different water types such as those we have investigated.

Absorption is a key parameter in marine optics. During the last decade, many studies were conducted in order to improve the methodology of its measurement in relation to investigations of primary productivity or remote sensing Although some aspects remain to be clarified (the $\beta$ factor in particular), absorption measurements are now reliable. In this study, in vivo light absorption was used to describe the medium through the action of particles and YS. Important spatial variations were observed between the stations investigated. These variations depended on whether the water was influenced by emergent lands (absorption dominated by non-living particles and YS) or by the ocean (absorption dominated by phytoplankton). The spatial and temporal variations observed for $a^{*}{ }_{p h}(\lambda)$ are a very interesting result of this study. Variations in $a^{*}{ }_{p h}(\lambda)$ are inversely related to [chl $a+$ pheo] (and to TSP), as observed in other studies. This is probably caused by differences in the taxonomic composition of phytoplankton and intracellular adaptation of the pigments to environmental conditions (light and nutrients). For other purposes, specific absorption is necessary for quantum yield calculation.

Except during meteorological events such as tropical depressions or cyclones, coral reef waters are universally considered as being clear This is in fact the case, 
but this assumption must be relativized, as the optical properties of lagoonal waters differ according to the kind of island considered (high island or atoll). They also differ from those of the surrounding ocean. Furthermore, optical properties vary spatially and temporally within the lagoon of each island and thus cannot be regarded as being uniform. Such differences are likely to influence the spatial distribution of light-dependent benthic organisms, and the characteristics of their photosynthetic apparatus should vary because of photoadaptive processes. Differences in optical properties in the lagoons and in the ocean (i.e. above the outer reef slope) should be taken into account when photodependent metabolic activity of a whole reef (e.g photosynthesis or calcification) is assessed or modeled.

Acknowledgements. This study was partly supported by the Ministère des Territoires et Départements d'Outre-Mer (Bureau CORDET). The authors thank the Délégation à l'Environnement in French Polynesia and $\mathrm{Mr}$ J. Pélissier for logistical support. Three anonymous referees are acknowledged for helpful comments.

\section{LITERATURE CITED}

Babin M, Therriault JC, Legendre L, Condal A (1993) Variations in the specific absorption coefficient for natural phytoplankton assemblages: impact on estimates of primary production. Limnol Oceanogr 38(1):154-177

Baker KS, Smith RC (1980) Quasi-inherent characteristics of the diffuse attenuation coefficient for irradiance. Proc Soc photo-opt Instrum Eng, Ocean Optics VI 208:60-63

Baker KS, Smith RC (1982) Bio-optical classification and model of natural waters, 2. Limnol Oceanogr 27(3): 500-509

Bricaud A, Babin M, Morel A, Claustre H (1995) Variability in the chlorophyll-specific absorption coefficients of natural phytoplankton: analysis and parameterization. J geophys Res 100(C7):13321-13332

Bricaud A, Morel A, Prieur L (1981) Absorption by dissolved organic matter of the sea (yellow substances) in the UV and visible domains. Limnol Oceanogr 26:43-53

Bricaud A, Stramski D (1990) Spectral absorption coefficients of living phytoplankton and nonalgal biogenous matter a comparison between the Peru upwelling and the Sargasso Sea. Limnol Oceanogr 35(3):562-582

Butler WL (1962) Absorption of light by turbid materials. J opt Soc Am 52:292-299

Drollet J, Faucon M, Maritorena S, Martin PMV (1994) A minor coral mass bleaching event in Tahiti in 1993. Aust J mar Freshwat Res 45:1149-1156

Dustan P (1982) Depth-dependent photoadaptation by zooxanthellae of the reef coral Montastrea annularis. Mar Biol 68:253-264

Falkowski PG, Jokiel PL, Kinzie RA III (1990) Irradiance and coral5. In: Dubinsky $Z$ (ed) Coral reefs. Ecosystems of the world, 25. Elsevier Scientific Publishing Co. Amsterdam, p 89-107

Gordon HR (1979) Diffuse reflection of the ocean: the theory of its augmentation by chlorophyll a fluorescence at $685 \mathrm{~nm}$. A.ppl Optics 18(8):1161-1166

Gordon HR (1989a) Can the Lambert-Beer law be applied to the diffuse attenuation coefficient of ocean water? Limnol Oceanogr 34(8):1389-1409

Gordon HR (1989b) Dependence of the diffuse reflectance of natural waters on the sun angle. Limnol Oceanogr 34(8): $1484-1489$

Jerlov NG (1976) Marine optics. EIsevier Scientific Publishıng Co, Amsterdam, p 131-137

Kirk JTO (1975) A theoretical analysis of the contribution of algal cells to the attenuation of light within waters 11 . Spherical cells. New Phytol 75:21-36

Kurk JTO (1984) Dependence of relationship between inherent and apparent optical properties of water on solar altitude. Limnol Oceanogr 29(2):350-356

Kushıno M, Sugihara S, Okami N (1984) Influence of fluorescence of chlorophyll $a$ on underwater upward irradiance spectrum. La Mer (Tokyo) 22:224-232

Kishino M, Takahashi M, Okami N, Ichimura S (1985) Estimation of the spectral absorption coefficients of phytoplankton in the sea. Bull mar Sci 37(2):634-642

Lorenzen CJ (1966) A method for the continuous measurement of in vivo chlorophyll concentration. Deep Sea Res $13: 223-227$

Lyzenga DR (1981) Remote sensing of bottom reflectance and water attenuation parameters in shallow waters using aircraft and Landsat data. Int J remote Sens 2:71-82

Maritorena S (1996) Remote sensing of the water attenuation in coral reefs: a case study in French Polynesia. Int $\mathrm{J}$ remote Sens (in press)

Maritorena S, Morel A, Gentilı B (1994) Diffuse reflectance of oceanic shallow waters: influence of the water depth and bottom albedo. Limnol Oceanogr 39(7):1689-1703

Mitchell BG, Kiefer DA (1988a) Chlorophyll a specific absorption and fluorescence excitation spectra for light-limited phytoplancton. Deep Sea Res 35(5):639-663

Mitchell BG, Kiefer DA (1988b) Variability in pigment specific particulate fluorescence and absorption spectra in the northeastern Pacific Ocean. Deep Sea Res 35(5).665-689

Morel A (1988) Optical modeling of the upper ocean in relation to its biogenous matter content (Case I waters). J geophys Res 93 (C9):10 749-10 768

Morel A. Prieur L (1977) Analysis of variations in ocean color. Limnol Oceanogr 22(4):709-722

Nelson R, Robertson CY (1993) Detrital spectral absorption: laboratory studies of visible light effects on phytodetritus absorption, bacterial spectral signal, and comparison to field measurements. J mar Res 51:181-207

Pelevin VN, Rutkovskaya VA (1977) On the optical classification of ocean waters from the spectral attenuation of solar radiation. Oceanology 17(1):28-32

Presendorter RW (1961) Application of radiative transfer theory to light measurements in the sea. Union Géodesique et Géophysique Internationale. Monographie 1010 (Symposium on radiant energy in the sea): 11-29

Smith RC, Baker KS (1978a) The bio-optical state of ocean waters and remote sensing. Limnol Oceanogr 23(2):247-259

Smith RC, Baker KS (1978b) Optical classification of natural waters. Limnol Oceanogr 23(2):260-26i

Smith RC, Baker KS (1981) Optical properties of the clearest natural waters $(200-800 \mathrm{~nm})$. Appl Optics 20(2):177-184

Stavn RH (1988) Lambert-Beer Jw in ocean waters: optical properties of water and cissolved/suspended material, optical energy budgets. Appl Optics 27(2):222-231

Topliss BJ (1985) Optical measurements in the Sargasso Sea solar stimulated chlorophyll tluorescence. Oceanol Acta $8(3): 263-270$

Yentsch CS, Phinney DA (1989) A bridge between ocean optics and microbial ecology. Limnol Oceanogr 34(8):1694-1705 